Global Conferences Series:

Sciences and Technology (GCSST), Volume 3, 2020

The $1^{\text {st }}$ International Conference on Education, Sciences and Technology

DOI: https://doi.org/10.32698/tech3239

\title{
The Effects of Shooting Knowledge and Anxiety on the Self- confidence of Marine Soldier Students
}

\author{
Muchsin $^{1}$, Yetti Supriyati ${ }^{2}$, Komarudin $^{3}$ \\ ${ }^{1,2,3}$ Universitas Negeri Jakarta \\ "muchsin.djaelani@gmail.com
}

\begin{abstract}
This study was aimed to find out the relationship between shooting knowledge and anxiety on marine soldiers self-confidence. In the last 20 years, the researchers have not found a research report related to the effect of shooting knowledge and anxiety on students' self-confidence especially research conducted in Indonesia. Knowledge of shooting is the subject matter that is presented to students while attending basic military education. One of the factors that influence the success of a student soldier in completing military education is the level of anxiety of students themselves. This study is to obtain variable data on shooting knowledge using the written test method, while the variables of anxiety and self-confidence use the questionnaire method.Furthermore, knowledge of shooting and anxiety were set as independent variables while self-confidence was set as a dependent variable. Furthermore, the results of the study showed that: shooting knowledge has a significant positive direct influence on the self-confidence of marines soldier students; anxiety has a significant negative direct effect on the self-confidence of marines soldier students.
\end{abstract}

Keywords: Shooting knowledge, anxiety, self-confidence, and Marine soldier students.

\section{Introduction}

Marines are members of a military force which arerecruited, trained and organized specifically to carry out duties at sea and at landing operations in the context of a sea attack campaign. In unconditional skill mastery, besides the learning process, the learning process uses continuous systems and performance adaptability[1].

Educational activities are directed at increasing the professionalism of human resources in organizing the organization while the activities in the field of training are carried out to maintain and improve the capabilities and skills as well as cooperationwhich is directed towards realizing professional strength with high operational readiness to support operational tasks. Therefore, the education and training program is aimed at enhancing the abilities and skills of members, the readiness of combat elements and maintaining the ability to carry out the functions of the Indonesian Navy.Education is a place for someone to gain knowledge, where knowledge is a construction that is formed by connecting one intellectual component and then processed into simple information [2].

Anxiety under certain conditions is needed to act on worries and protect from danger. If we feel danger will occur, then the brain sends a message to the nervous system, which response by releasing

Copyright (C) 2019, the Authors. Published by Redwhite Press.

Page $\mid 77$

This is an open access article under the CC BY-NC license

(http://creativecommons.org/licenses/by-nc/4.0). 
adrenaline, so that with increasing adrenaline causes us to be alert and energetic and provide a boost of strength, and prepare to carry out attacks or self-defense.A soldier student experiences patterns of life change from civil society to the military requiring adjustments to new life patterns, this condition results in high pressure resulting in high levels of anxiety at the beginning of military education [3]. While other studies say that life in the military and its activities is a factor that creates pressure for new personnel entering military institutions [4].

Students of soldiers who are studying are not free from feeling amused, because anxiety is a general feeling, feeling fear or losing the self-confidence that is not clear. Research related to anxiety carried out byGould, Petlichkoff, and Simons[5] says that somatic anxiety affects the performance of gun firing [5]. Likewise, the results of research conducted by[6] say that an athlete who shows high self-esteem will lower cognitive and somatic anxiety levels.The same is the result of Hammermeister's research [7] with the object of the research of 82 Stryker Brigade soldiers in the Pacific Northwest Military Post explaining that anxiety has a performance impact, both due to the influence of cognitive functions and somatic processes. Stress can result in significantly reducing cognitive performance in solving arithmetic problems [8]. Likewise, the results of the Chung study say that anxiety and anxiety will have an impact and influence on shooting performance [9].

A soldier student in the course of education is of course expected to be able to receive the knowledge he has learned. Knowledge is a process through sensing a particular object. Sensing occurs through the five human senses, namely the senses of vision, hearing, smell, taste, and touch. Likewise, knowledge is the strengthening of the material learned from various materials, specific facts and theories then brought to mind the appropriate information[10].Related to the knowledge learned in educational institutions, the main material is shooting knowledge, so that the material taught will greatly influence the results of education.Besides that, a soldier student must have high self-confidence in order to survive in various battlefields. A soldier must have a lot of experience on the battlefield so that his confidence will be higher, this is in accordance with the research conducted by Druckman and Bjork [11] said that someone who experiences repeated work, the self-confidence will increase, but what experience it is considered a failure, the confidence will decrease.

This is in accordance with the previous research report, namely by Copay [12], saying that the marksmanship learned in the training place was significantly influential on shooting performance. With the research subject, the police members concluded that mental training showed a significant increase in the accuracy of shootings [13].Likewise, research conducted byMaleki, Sanei, and Borhani [14] reports that military training has a significant positive effect on personalities, such as self-confidence, perfectionism, good ability, teamwork, and responsibility. Whereas the results of Kennedy's research,Kennedy and Sibley [15] say that military training serves to build a military base including noble behavior and self-confidence. The results of other studies say that the higher the level of cognitive and somatic anxiety, the lower the level of confidence [16].

Based on previous studies in this field, we decided to study the influence between knowledge of shooting, anxiety, and self-confidence of marine soldiers at the Surabaya Marine Education Command. And want to determine whether the features of shooting knowledge and anxiety have a positive or negative effect on the student's self-confidence.

\section{Methods and Materials}

This study employs a quantitative approach with causal survey methods and test methods. This research was carried out without any treatment from the researcher. The influence between variables was developed by applying path analysis. This method is aimed to find the effect of independent variables on the dependent variable. Then, this study examines three variables, namely two independent variables and one dependent variable. The independent variable consists of students 'shooting knowledge $\left(X_{1}\right)$, and students' anxiety $\left(X_{2}\right)$ while the dependent variable is self-confidence $\left(X_{3}\right)$. The research instrument that 
will be used to obtain respondent data is carried out by the process of validation and reliability of the instrument with expert tests, panelist tests, and empirical tests. The expert test was conducted by Gregory's method, while the panelist's test for knowledge instruments shot with the Lawshe method and instruments of anxiety and confidence with the Aiken's method. As for knowing the validity of the item empirically the instrument of knowledge shot with the formula Kuder Richardson (KR-20), while the instrument of anxiety and confidence with Product Moment.The research design is as follows.

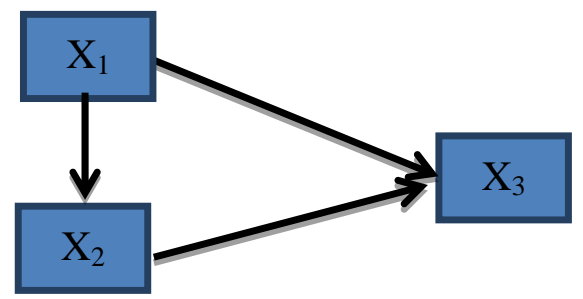

Figure 1. Research Design

This study involved 300 soldier students as the sample and each platoon was chosen randomly. In this study three data collection processes were carried out: (1) data on anxiety and confidence were obtained by questionnaire and (2) shooting knowledge data was obtained by a written test.

\section{Result and Findings}

3.1 Shooting knowledge data is a score obtained through a written test which has the highest score of 23, and the lowest 6 on average 14.67 and a standard deviation of 3.35. The average score of 14.67 lies in the interval $14-15$, so there are 69 or $23.00 \%$ of the soldier students included in the average group, 109 or $36.33 \%$ of the soldier students who arein below the average group and 122 or $40.67 \%$ of soldier-students are in above the average group.

3.2 Anxiety data is a score obtained through questionnaires. This data has the highest score of 151 and the lowest is 73 and the average is 126.07 with a standard deviation of 20.14. The average score of 126.07 is located in intervals $118-126$, so that there are 35 or $11.7 \%$ of soldier-students included in the average group, 79 or $26.33 \%$ of soldier-students who in the below average group, and 186 or $62.00 \%$ of soldierstudents are in the above average group.

3.3 Self-Confidence data is a score obtained through questionnaires. This data has the highest score of 183 and the lowest of 126 and an average of 155.06 with a standard deviation of 11.78 . The average score of 155.06 lies in the interval 154 - 160, so that there are 68 or $22.67 \%$ of the soldier students included in the average group, 67 or $22.33 \%$ of the soldier students who are in the group below the average, and 165 or $55.00 \%$ of soldier-students are in the above average group.

3.4 Requirements Analysis Test

Before inferential data analysis for testing the proposed hypothesis, firstly, requirement analysis was tested. The tests then were carried out regarding (1) the estimated error normality test, and (2) Linearity test and regression significance.

3.4.1 Estimated Normality Test

Tests for the normality of estimated error data were used by the Liliefors test. The estimated error is the difference in the observation score with the ideal (theoretical) score of the dependent variable (endogenous) of each regression equation which is formed. To test the hypothesis on the normality test, it was through the following procedure.Based on the calculation of data normality as stated in the attachment, the test results are obtained as follows. 
(a). Regression: $\widehat{X_{3}}=131,564+1,602 X_{1}, \mathrm{~L}_{\text {count }}=0,040 \mathrm{~L}_{\mathrm{tab}}=0,051$ so that the data is normally distributed.

(b) Regression: $\widehat{X_{3}}=202,175-0,374 \mathrm{X}_{2}, \mathrm{~L}_{\text {count }}=0,038 \mathrm{~L}_{\mathrm{tab}}=0,051$ so that the data is normally distributed.

Thus, it can be concluded that the data from the estimation error for the regression expression $X_{3}$ over $X_{1}$, and $X_{3}$ over $X_{2}$ are normally distributed.

3.4.2 Linearity Test

(a) Self-Confidence $\left(X_{3}\right)$ for Shooting Knowledge $\left(X_{1}\right)$

From the results of the analysis, it is known that the constants and regression equation coefficients $X_{3}$ over $X_{1}$ are 131.564 and 1.602 , so that the regression equation $\left(\widehat{X_{3}}\right)=131.564+1.602 X_{1}$ is obtained.

Statistical hypothesis:

$\mathrm{H}_{0}: \mathrm{X}_{3}=\alpha+\beta \mathrm{X}_{1}$. (linear regression)

$\mathrm{H}_{1}: X_{3} \neq \alpha+\beta X_{1}$. (nonlinear regression)

Based on the ANOVA table from the line of Deviation from Linearity for linearity test of the regression line equation, obtained $\mathrm{F}_{\text {count }}=1.016$ with $\mathrm{p}$-value $=0.44>0.05$ thus means $\mathrm{H}_{0}$ is accepted or the regression equation $X_{3}$ over $X_{1}$ is linear.

Statistical hypothesis:

$\mathrm{H}_{0}: \beta=0$ (regression is meaningless)

$\mathrm{H}_{1}: \beta \neq 0$ (regression means)

Based on the ANOVA table for testing the significance of the regression equation, it obtained $\mathrm{F}_{\text {count }}=$ 77,964 and $\mathrm{p}$-value $=0,000<0,05$. This means that $\mathrm{H}_{0}$ is rejected so that the regression equation $X_{3}$ over $\mathrm{X}_{1}$ is meaningful or significant.

(b) Self-Confidence $\left(\mathrm{X}_{3}\right)$ for Anxiety $\left(\mathrm{X}_{2}\right)$

From the results of the analysis, it is known that the constants and regression equation coefficients $X_{3}$ over $\mathrm{X}_{2}$, are 202,175 and $-0,374$, so the regression equation $\left(\widehat{X_{3}}\right)=202,175-0,374 \mathrm{X}_{2}$, is obtained.

Statistical hypothesis:

$\mathrm{H}_{0}: X_{3}=\alpha+\beta X_{2}$. (linear regression)

$\mathrm{H}_{1}: \mathrm{X}_{3} \neq \alpha+\beta \mathrm{X}_{2}$. (nonlinear regression)

Based on the ANOVA table from the line of Deviation from Linearity for linearity test

regression line equation, obtained $\mathrm{F}_{\text {count }}=0.998$ with $\mathrm{p}$-value $=0.490>0.05$, so that $\mathrm{H}_{0}$ is accepted or the $\mathrm{X}_{3}$ regression equation over $\mathrm{X}_{2}$, is linear.

Statistical hypothesis:

$\mathrm{H}_{0}: \beta=0$ (regression is meaningless)

$\mathrm{H}_{1}: \beta \neq 0$ (regression is meaningful)

Based on the table anova ${ }^{a}$ test for the significance of the regression equation, obtained $\mathrm{F}_{\text {count }}=205.758$ and $\mathrm{p}$-value $=0,000<0.05$. This means that $\mathrm{H}_{0}$ is rejected, so the regression equation $\mathrm{X}_{3}$ over $\mathrm{X}_{2}$, is significant.

\subsection{Hypothesis Test}

(a) The hypothesis proposed is that shooting knowledge $\left(\mathrm{X}_{1}\right)$ has a positive direct effect on self-confidence $\left(\mathrm{X}_{3},\right)$, the hypothesis tested:

$\mathrm{H}_{0}: \beta_{31} \leq 0\left(\mathrm{X}_{1}\right.$ does not have a direct positive effect on $\left.\mathrm{X}_{3}\right)$

$\mathrm{H}_{1}: \beta_{31}>0\left(\mathrm{X}_{1}\right.$ has a positive direct effect on $\left.\mathrm{X}_{3}\right)$

Based on the calculation of the path coefficient, it obtained $\rho_{31}=0.27$ with $t_{\text {count }}=5.94$. At the significance level of $5 \%$ or $\alpha=0.05$ it is known that $t_{\text {tab }}=1.64$. Because $t_{\text {count }}>t_{\text {tab }}$ then $H_{0}$ is rejected, which means shooting knowledge $\left(\mathrm{X}_{1}\right)$ has a positive direct effect on confidence $\left(\mathrm{X}_{3}\right)$. 
(b)The hypothesis proposed was anxiety $\left(\mathrm{X}_{2}\right)$ has a negative direct effect on self-confidence $\left(\mathrm{X}_{3}\right)$, the hypothesis tested:

$\mathrm{H}_{0}: \beta_{32} \geq 0\left(\mathrm{X}_{2}\right.$, does not have a direct negative effect on $\left.\mathrm{X}_{3}\right)$

$\mathrm{H}_{1}: \beta_{32}<0\left(\mathrm{X}_{2}\right.$, has a negative direct effect on $\left.\mathrm{X}_{3}\right)$

Based on the results of the calculation of the path coefficient, it obtained $\rho_{32}=-0.55$ with $\mathrm{t}_{\text {count }}=-12.19$ at the significance level of $5 \%$ or $\alpha=0.05$ it is known that $t_{\text {tab }}=-1.64$. Because $t_{\text {count }}<t_{\text {tab }} H_{0}$ is rejected, which means that anxiety $\left(\mathrm{X}_{2}\right)$ has a negative direct effect on confidence $\left(\mathrm{X}_{3}\right)$.

\section{Discussion and Conclusion}

The results showed that shooting knowledge had a direct positive effect on self-confidence, meaning that the high and low of self-confidence could be explained by shooting knowledge. Whereas the results of other parties' research supporting the conclusions above include the research conducted byHuber and Nichols [17] on improving patient service in hospitals, in conclusion, saying that training students who have knowledge of Evidence-Based Practices (EBP) will increase trust. himself towards performance in the field in dealing with patients. Likewise the results of research in Barber's [18] dissertation state that a consumer who has high knowledge tends to have a high level of confidence.

The results of the study showed that anxiety directly had a negative effect on self-confidence, which meant that high and low self-esteem could be explained by anxiety. This is also in accordance with the results of a study conducted byKoivula, et al., [6] on 178 Swedish athletes who were prepared to attend the 2004 summer Olympics and the 2006 Winter Olympics. Concluding that an athlete shows high selfconfidence then the level of cognitive anxiety and somatic is relatively low. Likewise, the results of Lawal and Idemudia [19]with a study sample of 206 Nigerian Federal University students stated that academic self-confidence has a direct influence on lower performance degradation and has an effect on anxiety (test) on tests.

Thus to make a soldier who has high trust, a soldier must educate with the ability to control his anxiety level. Therefore a soldier must be able to manage anxiety so that he is expected to have a high sense of confidence so that he will always be ready to carry out the tasks of activities carried out in educational institutions. Someone needs the self-confidence to reduce and control the emergence of anxiety related to problems in the future, so self-confidence is closely related to the level of anxiety.

The results showed that shooting knowledge had a direct negative effect on anxiety, meaning high and low anxiety can be explained by shooting knowledge. This is consistent with the results of a study conducted byDawood, Ghadeer, Mitsu, and Almuntary [20] at King Saud bin Abdul Azis University Riyadh with respondents from nursing students who concluded that there was a significant negative relationship between anxiety and academic level.

Anxiety is essentially owned by everyone, as well as a student soldier during the education period will always face various kinds of activities that require physical endurance, so that it will cause psychological and physical fatigue. In shooting knowledge material is taught directly when practicing in the field, this is done so that students immediately understand the procedures and procedures for shooting activities. Thus, students who have good shooting knowledge, it will reduce the level of anxiety so the student will be able to manage the level of anxiety.Likewise, the results of research by Kayihan, Erso"z, O"zkan [21] with a sample of 237 members of the Turkish Police Academy said that the anxiety level of the police officers had a significant effect on shooting performance. 


\section{Acknowledgment}

This research was achieved with the support of the research team and families.

\section{Reference}

[1] Arnold, P. M. M. R. D. (2008). Enhancing Military Training Through the Application of Maximum and Typical Performance Measurement Principles. International Society for Performance Improvement, 47(3), 29-35.

[2] Spuzic, S., Xing, K., \& Abhary, K. (2008). Some Examples of Ambiguities in Cross-disciplinary Terminology AM ', (January).

[3] Harris R. Lieberman, J. Philip Karl, and P. J. N. (2014). Positive Effects of Basic Training on Cognitive Performance and Mood of Adult Females. Human Factors, XX(X), 1-11.

[4] Jane E. Myers, P. M. A. B. (2004). Stress, Wellness, and Mattering among Cadets at West Point: Factors Affecting a Fit and Healthy Force. Military Medicine, 169(6), 475-482.

[5] Daniel Gould, Linda Petlichkoff, Jeff Simons, and M. V. (1987). Relationship Between Competitive State Anxiety Inventory-2 Subscale Scores and Pistol Shooting Performance. Journal of Sport Psychology, 9, 33-42.

[6] Koivula, Nathalie, Hassmen, P., \& Fallby, J. (2002). The Open Journal of Occupational Therapy. Elsevier Science Ltd, 865-875.

[7] Hammermeister, L. C. O. and J. (n.d.). Effects of Concentration Disruption on Simulated Basic Rifle Marksmanship Scores Among Stryker Brigade Soldiers. Journal of Instructional Psychology, 38(2), 105-108.

[8] Scribner, D. R. (2015). Predictors of Shoot-Don't Shoot Decision-Making Performance: An Examination of Cognitive and Emotional Factors. Journal of Cognitive Engineering and Decision Making, $X X(\mathrm{X}), 1-11$.

[9] Gregory K. W. K. Chung, Harold F. O’Neil, G. C., \& Bewley, D. \& W. L. (2010). The Role of Anxiety on Novices' Rifle Marksmanship Performance. Educational Assessment, 10(3).

[10] Cullinane, A. (2015). Bloom' s Taxonomy and its Use in Classroom Assessment, (October).

[11] Daniel Druckman and Robert A. Bjork. (1994). Learning, Remembering Believing Enhancing Human Performance. Washington D.C: National Academy Press.

[12] Copay, M. T. C. and A. G. (2013). Acquisition of marksmanship and gun handling skills through basic law enforcement training in an American police department. International Journal of Police Science and Management, 5(1), 16-30.

[13] Roger T. Couture, Mohan Singh, Wayne Lee, Paul Chahal, Leonard Wankel, M. O. and G. W. (1999). Can mental training help to improve shooting accuracy? An International Journal of Police Strategies \& Management, 22(4), 696-711.

[14] Maleki B., Sanei S., \&Borhani H., G. A.(2012). Effect of military training on personality traits of military students. Iranian Journal of Military Medicine, 13(4), 195-200.

[15] William G. Kennedy1, Ciara Sibley2, and J. C. (2015). Self-Confidence of Autonomous Systems in a Military Environment. Papers from the AAAI 2015 Fall Symposium, 10-17.

[16] Causer, J., Holmes, P. S. Smith, N. C. \& William, A. M. (2010). Anxiety, Movement Kinematics, and Visual Attention in Elite-Level Performers.

[17] Huber, K., \& Nichols, A. (2015). The Correlation between Confidence and Knowledge of EvidenceBased Practice among Occupational Therapy Students. The Open Journal of Occupational Therapy, $3(1), 1-17$.

[18] Barber, Nelson, M.S. (2008). How Self-Confidence and Knowledge Effects the Sources of Information Selected During Purchase Situation, Texas Tech University: Dissertation.

[19] Lawal \& Idemudia, E. S. (2017). Academic self-confidence effects on test anxiety among Nigerian 


\section{RedWhitepress Global Conferences Series: Sciences and Technology (GCSST), Volume 3, 2020}

university Academic self-confidence effects on test anxiety among Nigerian university students, 9(2)

[20] Eman Dawood, Hind Al Ghadeer, Rufa Mitsu, Nadiah Almuntary, B. A. (2016). Relationship between Test Anxiety and Academic Achievement among Undergraduate Nursing Students. Journal of Education and Practice, 7(2), 5765.

[21] Gurhan Kayihan, Gu“lfem Erso“z, Ali O “ zkan, M. K. (2013). Relationship between efficiency of pistol shooting and selected physical-physiological parameters of police. An International Journal of Police Strategies \& Management, 36(4). 